\title{
Knowledge, attitude, and barriers toward polio immunization among pre-clinical students in Malaysia
}

\author{
Theingi Maung Maung', Shivenanthini Kulandaivalu², Chee Mei Xian², \\ Kughan Ramachandra², Sankari Jai Devaraj' ${ }^{2}$, Thiviyaa Venkadason ${ }^{2}$, \\ Lubna Shirin ${ }^{3}$, Mohammed Shahjahan Kabir ${ }^{4}$
}

\begin{abstract}
${ }^{1}$ Associate Professor, ${ }^{2}$ Student, Department of Community Medicine, Faculty of Medicine, AIMST University, Bedong, Kedah, Malaysia, ${ }^{3}$ Senior Lecturer, ${ }^{4}$ Associate Professor, Department of Anatomy, Quest International University, Ipoh, Perak, Malaysia
\end{abstract}

\section{A B S T R A C T}

Background: Polio is reported as reemerging disease in Malaysia after 27 years of being free from it. It is important to identify the awareness towards polio vaccine among the medical students who are the future and the pillars of the nation, to develop a country. Aims and Objectives: This study aims to assess the knowledge, attitude, and barriers toward polio immunization among pre-clinical medical students. Materials and Methods: A crosssectional study was conducted among 190 pre-clinical students from a private university after obtaining informed consent and institutional ethical clearance. Data collected from Google Forms questionnaire were analyzed using SPSS version 20. Results: Insufficient knowledge, especially on disease nature, transmission, and correct dosage of vaccine, was noticed. Findings revealed that $79.5 \%$ of the students showed unfavorable attitude toward polio immunization. Year 2 students are more positive toward the vaccination compared to year 1. Main barriers toward polio immunization selected by the respondents are disagreement from the spouse, insecure about vaccine safety, and distance of the health center. Conclusion: Preclinical students should enhance their knowledge to be able to recognize the various barriers of polio immunization in our country and be part of the effort in solving these barriers as polio eradication is critical to ensuring a healthier future for children.

Key words: Knowledge; Attitude; Barriers; Polio immunization; Pre-clinical students
Access this article online

\section{Website:}

http://nepjol.info/index.php/AJMS

DOI: 10.3126/ajms.v12i11.38462

E-ISSN: 2091-0576

P-ISSN: 2467-9100

Copyright (c) 2021 Asian Journal of Medical Sciences

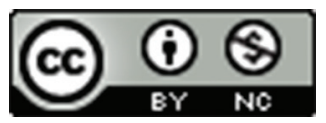

This work is licensed under a Creative Commons Attribution-NonCommercial 4.0 International License.

\section{INTRODUCTION}

Poliomyelitis or better known as polio has been part of human life since 1580 B.C. However, it only has been accredited as a serious disease in the 1970s. ${ }^{1}$ In general, poliomyelitis is an inflammation of the spinal cord. ${ }^{2}$ As described by its name, it is an infectious disease that affects various parts of the human body causing paralysis and eventually leads to death. Poliomyelitis is caused by a virus known as poliovirus which is from the Picornaviridae family and the Enterovirus genus. ${ }^{3}$ Poliovirus can invade the nervous system and can cause acute flaccid paralysis. Children under 5 are mostly affected by this. ${ }^{4}$ It can be either due to affected motor neurons or paralysis of muscles of respiration or throat which leads to death. However, death can only happen in extreme conditions, and it is uncommon. ${ }^{5}$ Therefore, knowledge on the transmissibility of poliovirus is crucial to curb the diseases from spreading. This study aimed to find out knowledge, attitude, and barriers toward polio immunization among pre-clinical students in a private university of Malaysia.

Malaysia encountered the very first polio outbreak in 1992 due to the spreading of poliovirus from the countries in the Indian subcontinent. However, the government was able to eradicate the disease and announced Malaysia as a polio-free country in 2020. After 27 years, the disease again reported 
in Malaysia in September 2019. To control the disease in Malaysia, the government takes some precautionary steps such as immunization. To create awareness among the public, health ministry conducts talks on polio and distributes pamphlet and brochures on polio. In addition, the health of the ministry urges the public to follow the National Immunization Schedule to curb the polio among the children. Even, the government introduces mandatory vaccination and provides free of cost vaccination. ${ }^{6}$

The barriers in the efforts of polio eradication are logistical, management challenges, uncertain funding, political tension, persisting anti-immunization rumors, and resistance. However, the acceptance of the public toward the immunization remains dominant. Negative communications about polio immunization in Nigeria resulted in decrease acceptance of vaccines in five states in North Nigeria. Political influence was another cause of the polio immunization boycotts. ${ }^{7}$

The progress of "End Polio from Pakistan" was impeded due to security risks to health care workers, false religious and traditional beliefs, and limited access to communities that are hard to reach. Major barriers toward polio immunization include lack of knowledge and misconceptions about polio immunization. Low oral polio vaccine (OPV) coverage in higher conflict areas of Pakistan, parents' misperceptions about poliovirus and OPV, and lack of parental trust on local health care workers were reported by a survey conducted by Harvard Opinion Research Program in collaboration with UNICEF. ${ }^{8}$

This study aims to find out the knowledge toward polio among preclinical students in one private institution in Malaysia. The youths are the future and the pillars of the nation, to develop a country. The students are the weapons to build the nation with all their knowledge and education. If medical students are not well educated about polio and vaccine, it increases the possibility that Malaysia can never see a polio free future. Moreover, it is important to carry out this study at this point of time as polio has become a reemerging disease in Malaysia after 27 years of being free from it.

\section{Aims and objectives}

This study aims to assess the knowledge, attitude, and barriers toward polio immunization among pre-clinical medical students.

\section{MATERIALS AND METHODS}

A cross-sectional study was carried out as a research project from March to September 2020 in a private medical school in the Kedah State, Malaysia. The ethical approval for conducting this study was obtained from the institutional ethical clearance committee. The ethical approval for conducting this study was obtained from the institutional ethical clearance committee. Data collection for the survey was conducted for 2 months. An additional 2 months were needed to analyze the collected data. Finally, report writing for the study took about 2 months. Altogether it took about 6 months to complete the study. A total of 190 students from pre-clinical year were taken as sample by convenient sampling method. Almost equal proportion of students from year 1 to year 2 was involved in this study. According to inclusion criteria, year 1 and year 2 medical students of both genders from different ethnic backgrounds were taken as participants. As for the exclusion criteria, medical students from year 3 to 5 and students from other courses were not considered as participants. A structured questionnaire in the form of Google Forms was used in this study which consists of three sections (knowledge, attitude, and barriers). The questionnaire was adapted from an established research article. ${ }^{8}$ The content validity was verified by the researchers. The reliability coefficient of the questionnaire was calculated using SPSS v.20. The Cronbach's alpha value of questionnaires 0.72 and 0.78 was computed for knowledge and attitude section. As for the ethical consideration, informed consent was distributed to the participants and explained in detail. The participant who refuses to participate was excluded from the study sample. All the information provided by the participants were disclosed only to the members who conducted the study. The data collection was proceeded only after the approval from the institutional ethical committee to conduct this study and the approval number is FOM/SSM/2020/016. The purpose of the study was explained to the study participants, anonymity, privacy, and confidentiality were ensured. This study was conducted in accordance with the Declaration of Helsinki.

\section{Statistical analysis}

The data were transferred and recorded in the SPSS software which was used to derive suitable tables, graphs, and diagrams for data presentation. For inferential analysis, Chi-square test and independent t-test were performed to draw out the suitable conclusion. $\mathrm{P}=0.5$ and small was considered as statistically significant. Five-point Likert scale was given to the respondents for attitude questions, and they were asked to state their level of agreement from "strongly disagree," "disagree," "undecided," "agree," or "strongly agree." If the scores for attitude obtained by the respondent were $\geq 80 \%$, it was considered as having favorable attitude and those whose score $<80 \%$ were considered as unfavorable attitude. 


\section{RESULTS}

\section{Sociodemographic characteristics}

Demographic information on the gender, age, year of study, race, religion, birthplace, accommodation, and past experience with polio patients are assessed. In this study, $58.42 \%$ of the participants are female and $41.58 \%$ of the participants are male. The mean age of the participants 20.71 years old and the standard deviation is 0.984 . The youngest participant who participated in this study is 19 years old and the oldest participants who participated in this study is 27 years old. Age distribution of the respondents is skewed to right. Out of 190 respondents, $52.63 \%$ of the participants are from year 1 to $47.37 \%$ which are from year 2. The number of participants from both batches is almost equal. More than half (57.89\%) of the participants are Indians followed by $38.42 \%$ who are Chinese and 2.1\% who comprise of Malays. The remaining $1.60 \%$ is other races. Results show that $50.5 \%$ of the participants are Hinduism, followed by 30.53\% which are Buddhism, 10.53\% who are Christian, 5.3\% are Islam, and $3.16 \%$ for other religion. Based on the findings, $68.95 \%$ of them are from West Malaysia, 25.26\% are from East Malaysia, and 5.79\% are non-Malaysian. Majority of the students $(96.84 \%)$ has no past experience with polio patient while $3.16 \%$ of them have past experience with polio patients.

Knowledge regarding poliomyelitis among participants Different items involved in the knowledge questionnaire which include the nature of the disease (Q1), causative agent (Q2), signs and symptoms (Q3 and 4), risk factors (Q5 and 6), mode of transmission (Q7 and 8), management and prevention $\left(Q^{9}-11\right)$, and the severity of disease (Q12). Year 1 and 2 students have better understanding toward polio in nature of disease, causation risk factors, prevention, and severity by showing 68\%-93\% correct answers (Table 1). The highest response to correct answers is seen in the statements "Poliomyelitis is caused by virus" and "Lack of immunization is a risk factor." However, weak responses can be seen in presenting symptoms, mode of transmission, curability, and immunization (20-50\%). More than half $(52.6 \%)$ of the respondents agree to the negative statement that polio can be transmitted through direct contact from person to person and 33.7\% agree to another negative statement, only two doses of polio vaccines in National Immunization Schedule.

\section{Attitude of participants toward poliomyelitis}

Attitude related to the nature of disease, severity of disease, importance of vaccination, handling of vaccines, contagiousness of disease, role of community in controlling poliomyelitis, and the productivity of people with poliomyelitis is assessed through Google Forms.

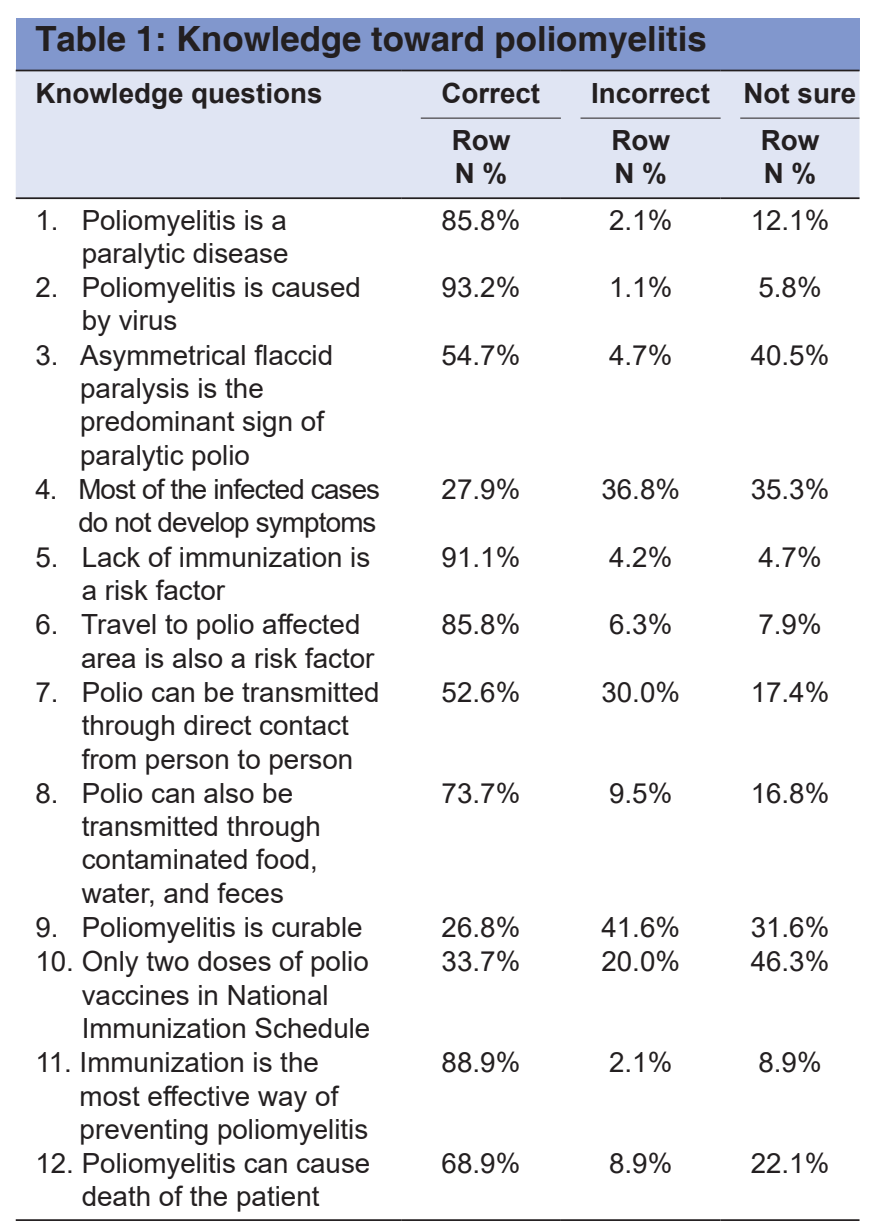

Independent t-test was performed to determine the attitude toward poliomyelitis and polio vaccination among the respondents (Table 2). The more agreement of "Polio is a very serious disease," "All children should be vaccinated for Polio," and "Communities should actively participate in controlling Poliomyelitis in Malaysia." MBBS year 2 students agree more to the statement "Communities should actively participate in controlling poliomyelitis in Malaysia," showing the significant P-values. However, year 1 students agree more to the statements "Polio vaccines are not capable to reduce the transmission of infection," "Infected children should not be brought to public place because of risk of infection transmission," and "People with poliomyelitis are less productive than non-disabled ones" with statistically significant result.

Attitude toward polio vaccination and year of study Of 190 students, 151 (79.5\%) showed unfavorable attitude and $39(20.5 \%)$ showed favorable attitude (Table 3). The scale measured attitude from maximum score of 32 and minimum score of 11 . Mean attitude score in this study was $23.74 \pm 2.60$. Score of 26 and above was considered as favorable attitude and lower than 16 was unfavorable. Chi-square analysis showed significant association between 
attitude level and participant's year of study (Table 3). Year 1 students had negative attitude toward polio immunization than year 2 students $(\mathrm{OR}=0.42, \mathrm{P}<0.05)$.

Participants understanding about barriers toward polio immunization

Barriers related to the prevention of disease, willingness of parents to bring children for vaccination, misinformation on polio vaccine, the importance of polio vaccination,

\begin{tabular}{|c|c|c|c|c|}
\hline $\begin{array}{l}\text { Attitude } \\
\text { questions }\end{array}$ & $\begin{array}{c}\text { Total } \\
(\text { Mean } \pm S D)\end{array}$ & $\begin{array}{c}\text { Year } 1 \\
(\text { Mean } \pm S D)\end{array}$ & $\begin{array}{c}\text { Year } 2 \\
(\text { Mean } \pm S D)\end{array}$ & P-value \\
\hline $\begin{array}{l}\text { Poliomyelitis is } \\
\text { a very serious } \\
\text { disease }\end{array}$ & $3.35 \pm 0.69$ & $3.34 \pm 0.69$ & $3.36 \pm 0.68$ & 0.875 \\
\hline $\begin{array}{l}\text { Polio vaccines } \\
\text { are not capable } \\
\text { to reduce the } \\
\text { transmission of } \\
\text { infection }\end{array}$ & $2.95 \pm 0.83$ & $3.37 \pm 0.55$ & $2.57 \pm 0.97$ & $0.000^{\star \star \star}$ \\
\hline $\begin{array}{l}\text { Polio vaccines } \\
\text { should be } \\
\text { appropriately } \\
\text { stored to be } \\
\text { effective }\end{array}$ & $3.27 \pm 0.55$ & $3.24 \pm 0.57$ & $3.31 \pm 0.53$ & 0.377 \\
\hline $\begin{array}{l}\text { Infected children } \\
\text { should not be } \\
\text { brought to public } \\
\text { place because of } \\
\text { risk of infection } \\
\text { transmission }\end{array}$ & $2.87 \pm 0.87$ & $3.01 \pm 0.79$ & $2.71 \pm 0.92$ & $0.019^{*}$ \\
\hline $\begin{array}{l}\text { All children should } \\
\text { be vaccinated for } \\
\text { polio }\end{array}$ & $3.62 \pm 0.49$ & $3.55 \pm 0.50$ & $3.69 \pm 0.49$ & 0.06 \\
\hline $\begin{array}{l}\text { Communities } \\
\text { should actively } \\
\text { participate } \\
\text { in controlling } \\
\text { poliomyelitis in } \\
\text { Malaysia }\end{array}$ & $3.57 \pm 0.55$ & $3.47 \pm 0.58$ & $3.68 \pm 0.49$ & $0.008^{* *}$ \\
\hline $\begin{array}{l}\text { People with } \\
\text { poliomyelitis are } \\
\text { less productive } \\
\text { than non-disabled } \\
\text { ones }\end{array}$ & $2.72 \pm 0.71$ & $2.85 \pm 0.69$ & $2.58 \pm 0.70$ & $0.008^{* *}$ \\
\hline
\end{tabular}

and the efficiency of polio vaccine were asked in this study (Figure 1). The highest agreement can be seen in the statements "Anyone between the spouses does not want their child to receive Polio vaccination," "There are many safety issues with Polio vaccine," and "There is no nearby health-care facilities can provide Polio immunization," showing "yes" percentage of $14.4 \%, 13.3 \%$, and $10 \%$, respectively. Respondents less believed the statements such as "Most of the polio vaccines provided by Malaysian are defective" and "Vaccination is considered harmful for children, showing $4.2 \%$ and $4.6 \%$ responses."

\section{DISCUSSION}

In this study, there were more female participants (58.4\%) compared to male participants (41.6\%). This is mainly due to female performance on school level education which is far better than male in Malaysia which gives them enough qualification to enroll to the courses they prefer. In addition, most of participants in this study were Indians (57.89\%) which contradict with the survey conducted in Universiti Sultan Zainal Abidin (UnisZA) where Malay ethnic group was high $(70.3 \%)$. The difference in ethnical distribution

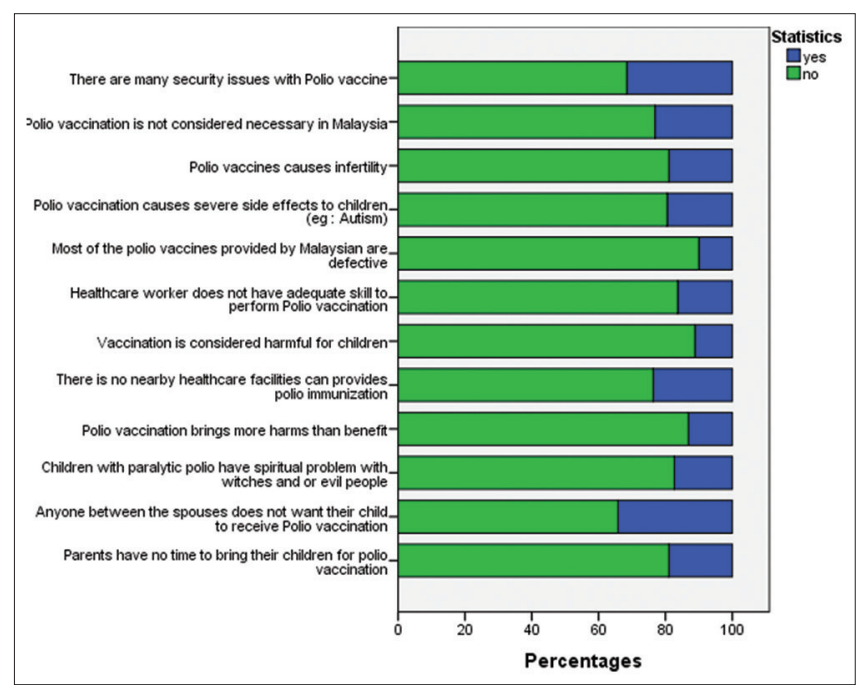

Figure 1: Barriers toward polio immunization

Table 3: Association between attitude toward polio vaccine and year of study

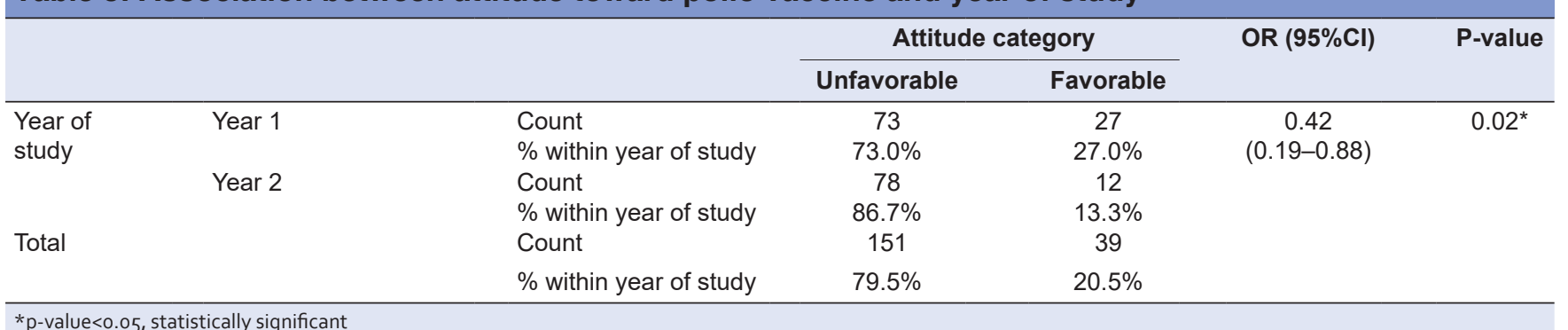

*p-value $<0.05$, statistically significant 
in both surveys may be due to entry requirement to private university which is based on seat availability (quota system) and also depends on entry requirement of desired courses. Followed by this, two-third of participants from this study is from West Malaysia because of the strategic location of AIMST University and lower living cost in Kedah. ${ }^{9}$

Based on Table 1, the correct answer given by respondents is varying from $20 \%$ to $93 \%$, yet their knowledge on nature, transmission, and correct dosage of vaccine is deprived. Only 30\% of students aware that polio virus does not transmit through direct contact. The respondents showed insufficient knowledge related to presenting symptoms, mode of transmission, curability, and immunization. These findings support another findings from a survey conducted in medical schools of France by Kernéis et al., regarding students' education about vaccination where one-third of the students insufficiently prepared for questions about vaccination, especially for communicating with patients on side effects and strategies to respond to vaccine hesitancy. ${ }^{10}$ The most likely reason of insufficient knowledge in this study is students who do not pay much attention to polio as it has been eradicated in Malaysia. Based on the curriculum adopted in recent university, students from clinical years can get more exposure to topics related to vaccine preventable diseases. Since study population in this study includes pre-clinical students, their exposure to vaccine-related topics can be insufficient. In addition, nearly one-third of the students do not aware of the number of doses of poliomyelitis vaccines given to peoples according to National Immunization Schedule. In Malaysia, inactivated polio vaccine was given at the age of 2, 3 and 5 months as per National Immunization Schedule. ${ }^{11}$ Although Malaysia was declared polio free in 2000, there was polio outbreak in Sabah State 19 years after the declaration. In addition to routine vaccination, additional vaccines were given to both Malaysians and foreign children below the age of 5 in Sabah area. ${ }^{12}$ Students should aware about the country situation, especially related to public health measures. Polio can be chosen as one of the discussion topics in the seminar or posters for preclinical students to raise their awareness and to improve their knowledge.

In this study, $73.2 \%$ of the students displayed positive attitude toward the polio vaccines which are capable in reducing the transmission of infection. Year 2 students showed more awareness toward community involvement in polio control, and they agreed less to the negative statements (Table 2). In the recent university, starting from year 3, students start to expose to clinical postings at the hospitals. Curriculum was prepared in such a way that more topics related to natural history and epidemiology of vaccine preventable diseases for year 2 than year 1 . To overcome this unsatisfactory attitude, the education system in the university should be improved and more information regarding polio should be taught. Internet and social media play a pivotal role at the present time as large gatherings or seminars cannot be carried out due to COVID-19 pandemic. University should utilize this as an opportunity by organizing conference on polio and/or games virtually to teach students about polio vaccine and its benefits as some are still ignorant toward polio vaccine.

Association between participants' attitude and year of study is displayed in Table 3 and year of study was significantly related to their attitude toward polio immunization. This finding support finding in another study carried out in Pakistan by Khan et al., where higher education was associated to better attitude. ${ }^{8}$ As for the overall attitude, $79.5 \%$ of pre-clinical students showed unfavorable attitude and $20.5 \%$ showed favorable attitude. This finding is quite alarming because of high percentage of unfavorable attitude among the medical students of clinical years. This is contradicted to another finding in the survey that was carried out among the Muslims parents in Malaysia. Positive attitude and good perception toward vaccination process was noticed among the respondents although Malaysia is Muslim dominant country. Majority of Malaysian Muslim parents believed that "vaccine is not prohibited in Islam" and most of them also rejected the belief that "all vaccines are non halal and hence should be avoided."13

Findings revealed that $13.3 \%$ of the respondents believed that many safety issues with polio and a few respondents $(4.2 \%)$ thought that vaccines were defective (Figure 1). Although vaccine-associated paralytic poliomyelitis was noticed after introduction of OPV, real adverse effects of OPV were quite rare by Safurah and Afar. ${ }^{11}$ The statement "anyone between the spouses does not want their child to receive Polio vaccination" was agreed by $14.4 \%$ of the students. Vaccine hesitancy was noticed nowadays in the general population and even among general practitioners and family physicians. A systematic review by Collange et al., stated that the common reasons for non-vaccination were the belief that frequent exposure already protected them, concerns about side effects, forgetfulness, and doubts about the vaccine's efficacy. ${ }^{14}$

Another barrier toward polio immunization chosen by the respondents was people cannot access vaccination because of far distance to health center. At least half of the world's population does not have access to health services according to the World Health Organization. ${ }^{15}$ Although Malaysia has excellent medical facilities, there is still a lack of health-care services in the rural and remote regions. ${ }^{16}$ In 2018, Malaysia vowed to strengthen primary health-care system as it plays a key role in bringing health services closer to people's homes and communities as demonstrated in a 
study done by Noor and Abdullah. ${ }^{17}$ After declaration of the polio outbreak in Malaysia in December 2019, health authorities immediately mobilized health care workers in an immunization campaign to stop the spread of the disease and to overcome the unmet need. They also arranged fixed sites for parents to bring their children for vaccination, implemented drive-through and school immunization campaign, and went house to house to focus on reaching the highly mobile populations. Government also provided flying doctor service in Sabah to ensure the immunization services reach the rural population. ${ }^{18}$

Role of parents, health personal, policy-makers, media, and ultimately everyone is important to ensure that every child gets the vaccines they need. Finding in this study pointed out that not only in public but awareness should also be raised among the medical students who will become future doctors. According to the goal of World Immunization Week 2021, with the theme "Vaccines bring us closer," we must show how vaccination connects us to the people, helping improve the health of everyone, everywhere throughout life. ${ }^{19}$ Therefore, strong initial training of medical students is essential to enable them to fulfill a primary role in vaccination.

\section{CONCLUSION}

Knowledge related to polio and vaccination is insufficient among the pre-clinical medical students. The attitude of the students toward the polio vaccine is also unfavorable. This study clarified that year 2 students have much knowledge on polio compared year 1 and they also showed better attitude than their counterparts. To raise awareness for polio immunization, topic related to polio can be included in symposiums and more area related to polio can be given to their lectures, especially in microbiology. Carrying more weightage in the academic performance can also enhance the students' learning related to polio.

\section{ACKNOWLEDGMENT}

Authors would like to thank AIMST University Research Ethical Committee (FOMRHAEC) for giving permission to carry out the study. Students for helping in gathering data used in the study and all respondents from Faculty of Medicine for taking time to answer the questionnaires.

\section{REFERENCES}

1. History of Polio GPEI. Available from: https://www. polioeradication.org/polio-today/history-of-polio. [Last accessed on 2021 Jul 16].

2. Mehndiratta MM, Mehndiratta $\mathrm{P}$ and Pande R. Poliomyelitis:
Historical facts, epidemiology, and current challenges in eradication. Neurohospitalist. 2014;4(4):223-229.

https://doi.org/10.1177/1941874414533352

3. Heriyanto B, Susanti N and Setiawaty V. Characterization and Identification of Poliovirus from the Environment in Indonesia 2015. Bali Med J. 2018;7(3):539-543.

https://doi.org/10.15562/bmj.v7i3.963

4. Sarada AK, Thilak SA and Neloopant SA. A cross sectional study on awareness about injectable polio vaccine among pregnant women and mothers of children under 14 weeks in a rural area of Kannur, North Kerala, India. Int J Community Med Public Health. 2016;3(8):2004-2007.

http://dx.doi.org/10.18203/2394-6040.ijcmph20162186

5. Ghafoor $S$ and Sheikh N. Eradication and Current Status of Poliomyelitis in Pakistan: Ground Realities. J Immunol Res. 2016;2016:6837824.

https://doi.org/10.1155/2016/6837824

6. The Response to Polio in Malaysia Academy of Medicine What You Think Malay Mail. Available from: https://www.malaymail. com/news/what-you-think/2019/12/15/the-response-to-polio-inmalaysia-academy-of-medicine/1819336. [Last accessed on 2021 Jul 16]

7. Oku A, Oyo-Ita A, Glenton C, Fretheim A, Eteng G, Ames H, et al. Factors affecting the implementation of childhood vaccination communication strategies in Nigeria: A qualitative study. BMC Public Health. 2017;17(1):200.

https://doi.org/10.1186/s12889-017-4020-6

8. Khan MU, Ahmad A, Aqeel T, Salman S, Ibrahim Q, Idrees J, et al. Knowledge, attitudes and perceptions towards polio immunization among residents of two highly affected regions of Pakistan. BMC Public Health. 2015;15(1):1100.

https://doi.org/10.1186/s12889-015-2471-1

9. Haque, Rahman NA, Majumder MA and Rahman NI. Assessment of academic/non-academic factors and extracurricular activities influencing performance of medical students of faculty of medicine, Universiti Sultan Zainal Abidin, Malaysia. Adv Hum Biol. 2018;8(1):3.

https://doi.org/10.4103/AlHB.AlHB_28_17

10. Kernéis $S$, Jacquet $C$, Bannay $A$, May $T$, Launay $O$, Verger $P$, et al. Vaccine education of medical students: A nationwide crosssectional survey. Am J Prev Med. 2017;53(3):e97-e104. https://doi.org/10.1016/j.amepre.2017.01.014

11. Safurah DR and Afar J. Vaccination Program: Governance and Policy Decision Process in Malaysia. Ministry of Health Malaysia; 2017.

12. Fourth Polio Case Hits Malaysia, Unvaccinated Foreign Sandakan Boy CodeBlue. Available from: https://codeblue. galencentre.org/2020/03/10/fourth-polio-case-hits-malaysiaunvaccinated-foreign-sandakan-boy. [Last accessed on 2021 Jul 15].

13. Ansari MT, Jamaluddin NN, Ramlan TA, Zamri N, Majeed S, Badgujar V, et al. Knowledge, attitude, perception of Muslim parents towards vaccination in Malaysia. Hum Vaccin Immunother. 2021;17(3):785-790. https://doi.org/10.1080/21645515.2020.1800325

14. Collange $F$, Verger $P$, Launay $O$ and Pulcini $C$. Knowledge, attitudes, beliefs and behaviors of general practitioners/family physicians toward their own vaccination: A systematic review. Hum Vaccines Immunother. 2016;12(5):1282-1292. https://doi.org/10.1080/21645515.2015.1138024

15. World Bank and WHO. Half the World Lacks Access to Essential Health Services, 100 Million Still Pushed into Extreme Poverty Because of Health Expenses. Geneva: World Health 
Organization. Available from: https://www.who.int/news/ item/13-12-2017-world-bank-and-who-half-the-world-lacksaccess-to-essential-health-services-100-million-still-pushedinto-extreme-poverty-because-of-health-expenses. [Last accessed on 2021 Jul 16].

16. Accessibility to Health Care Services and Other Facilities in Malaysia Challenges Media. Available from: http:// challengesmedia.com/3599-2. [Last accessed on 2021 Jul 16].

17. Noor DD and Abdullah H. Office of the DG of Health Malaysia;
2019.

18. Going the Extra Mile to Protect Children Against Polio During the Pandemic. Available from: https://www.who.int/malaysia/ news/feature-stories/detail/going-the-extra-mile-to-protectchildren-against-polio-during-the-pandemic. [Last accessed on 2021 Jul 16].

19. World Immunization Week; 2021. Available from: https://www. who.int/campaigns/world-immunization-week/2021. accessed on $2021 \mathrm{Jul} 16]$.

\section{Authors' Contributions:}

TMM-Interpreted the results, review the literature, and manuscript preparation; SK, CMX, and KR-Concept and design of the study, coordination; SJ and TV-Statistical analysis and prepared first draft of manuscript; LS and MSK-Coordination and revision of the manuscript.

Work attributed to:

AIMST University, Bedong, Kedah, Malaysia.

\section{ORCID ID:}

Dr. Theingi Maung Maung - (D) https://orcid.org/0000-0002-4023-1992

Ms. Shivenanthini Kulandaivalu - (1) https://orcid.org/0000-0002-6393-5335

Ms. Chee Mei Xian - (1) https://orcid.org/0000-0001-5445-2908

Mr. Kughan Ramachandra - (D) https://orcid.org/0000-0002-7564-3567

Ms. Sankari Jai Devaraj - (1) https://orcid.org/0000-0002-0288-719X

Ms. Thiviyaa Venkadason - (1) https://orcid.org/0000-0002-8366-7593

Dr. Lubna Shirin - (1) https://orcid.org/0000-0001-7502-8284

Dr. Mohammed Shahjahan Kabir - (1) https://orcid.org/0000-0002-1257-6432 